\title{
An Empirical Study of the Creativity, Imagination, and Design Thinking of Taiwanese Design Undergraduates
}

\author{
Kuan-Chen Tsai \\ Department of Applied Digital Media, WuFeng University \\ 117, Sec. 2, Chiankuo Rd., Minhsiung, Chiayi County 62153, Taiwan \\ E-mail: tsaikuanchen@wfu.edu.tw
}

\begin{abstract}
Design thinking has been valued in business and education field. Design thinking uses creative approaches to problem solving, organizational development, and learning. For designers, the ultimate goal is to produce userfriendly and economic products that meet people's needs and desires. In order to achieve that goal, creativity, imagination, and design thinking have become necessary capacities for designers to transform abstract ideas into useful products and services successfully. The purpose of the current study was to examine the relationship among creativity, imagination, and design thinking of Chinese design undergraduates. Two research questions are asked: What is the relationship among creativity, imagination, and design thinking of our participants? Do gender and age affect these relationships? Based on structural equation modeling, we found that the relationships among creativity, imagination, and design thinking were strong and positive. Additionally, age and gender did not affect in these relationships. Although some limitations were discussed in the current study, the results provide unique value for future research.
\end{abstract}

Keywords: Challenge creativity, imagination, design thinking, structural equation modeling, Taiwanese undergraduates

DOI: $10.7176 / \mathrm{JEP} / 12-20-01$

Publication date:July $31^{\text {st }} 2021$

\section{Introduction}

Creativity, imagination, and design thinking are viewed as important ingredients of design education (Owen, 2006). For designers, the ultimate goal is to produce user-friendly and economic products that meet people's needs and desires (Brown, 2008). In order to achieve that goal, creativity, imagination, and design thinking have become necessary capacities for designers to transform abstract ideas into useful products and services successfully (Yang \& Hsu, 2020). As a result, from the design education perspective, how to unleash the potential of young designers has become an important agenda in the design curriculum.

In the design field, success in producing visual and material artifacts is important. Learning through designing has the advantage of facilitating students' cognitive, spatial, motor, social, and aesthetic skills (Kangas, Seitamaa-Hakkarainen, \& Hakkarainen, 2013). Therefore, bringing design thinking into the curriculum could be an important step to help students develop constructive learning (Scheer, Noweski, \& Meinel, 2012). Owen (2006) argues that design thinking is holistic and creativity is essential for design thinking, as creative thinking is a path toward invention. Furthermore, designers tend to visualize their ideas in a range of media. Through imagination, they exercise their concepts and transform them into concrete products. In short, design thinking, creativity, and imagination are valuable assets for design education. At the same time, these three variables are also promising research directions for design literature.

\section{Creativity}

Students of creativity have argued that creativity is multifaceted and complex (Hennessey \& Amabile, 2010) and is the key driving force of human society (Florida, 2002). Two major features are important to define creativity: novelty and appropriateness (Runco \& Jaeger, 2012). Although originality or novelty is treated as a criterion of creativity, it is important to recognize that creative ideas or products are not independent of its context; namely, the usefulness of the creative manifestation should be taken into consideration in order to justify the true value of creativity. Some scholars believe that creativity does not come cheap; rather, it requires at least ten years of deliberate practice and commitment (Csikszentmihalyi \& Nakamura, 2006; Sternberg \& O'Hara, 2000).

A large number of efforts have used different approaches to study the characteristics of creativity, and among them, cognitive-based research has dominated the creativity literature (Sternberg, 1999). More specifically, the processes of divergent thinking, ideas generation, and creative problem solving have been the major focus (Runco, 2004). Several variables have been identified as important catalysts of these process: disposition, knowledge, memory, intuition, and environment (Simonton, 2012). The trend of the cognitive approach is probably related to Guilford's (1950) seminal systematic study of creativity. Following this path, Torrance (1974) developed the world's most popular creativity test, the Torrance Tests of Creative Thinking (TTCT) and because of his contribution, Torrance is known as the "Father of Creativity" (Kaufman \& Baer, 
$2006 \mathrm{a}, \mathrm{p.}$ 1). The premise of this conceptualization is rooted in the belief that creativity is viewed as being an essential cognitive function (Sternberg \& O’Hara, 2000) and has an important optimizing function (Runco, 2010).

Another thread of research is the affect perspective of creativity (Kaufmann, 2003). Research has demonstrated that affect and mood might trigger different styles of information processing, which in turn impact on the performance of creative thinking (Kaufmann, 2003). Following this line of inquiry, Russ (1993) proposed the cognitive-affective theory of creativity in order to bridge two paradigms, thereby painting a clearer picture of creativity. Russ and her colleagues (Russ \& Kaugars, 2000; Russ \& Schafer, 2006) found that with the use of pretend play, children experience affect-laden fantasy, which directs the practice of divergent thinking. In other words, divergent thinking plays a mediator role between affect and creativity.

\section{Imagination}

Imagination and creativity are highly correlated. It is believed that engaging imagination can foster creativity performance (Tsai, 2012). Therefore, many scholars have underlined the need to develop students' imagination and creativity in order to equip them to face dynamic challenges, thereby maintaining a sustainable global society (Morosini, 2010). A number of studies have examined human imagination from different perspectives, such as visual imagery (Richardson, 1969), philosophical inquiry (Warnock, 1976), spatial conceptualization (Thurstone \& Thurstone, 1965), mental imagery (Marks, 1995), and imagery companions (Taylor, 1999).

Psychologists have believed imagination serving one of the higher mental functions that synthetically combines memories and experiences into a mental construction (Morosini, 2010). Lin, Hsu, and Liang (2014) categorized imagination as initiating imagination, conceiving imagination, and transforming imagination. Initiating imagination refers to exploring novel ideas, conceiving imagination is using personal intuition and sensibility to generate and concentrate on possible ideas, and transforming imagination refers to developing abstract ideas and reconstructing knowledge across different domains.

Gaut (2003) argued that creative people have an intendency to imagine different propositions, which affect the following developments that can generate appropriate solutions. Similarly, designers also need imagination in the process of developing prototypes. In order to create elegant products or action plans that meet users' needs, imagination can be considered as an important ingredient for exercising design thinking. Imagination could yield possibility thinking that can help designers generate products with appropriate functionality and economic use.

\section{Design Thinking}

Design thinking is treated as a complex thinking process where designers utilize mental strategies to conceive new realities, which contributes to the transformation and innovation of forming new activities (Tschimmel, 2012). Several important features of design thinking have been identified: (a) abductive thinking, thinking in new and different views related to future possibilities; (b) perceptive cognition, creating conscious and directed perception; (c) sketching, an extension of mental imagery; (d) prototyping, visualizing and testing new solutions; and (e) the human-centered approach, a joint method of working and co-creation (Tschimmel, 2012).

A number of design thinking models have been proposed over the past decades. The first, the IDEO 3I model (Brown, 2008), was developed by IDEO and the 3I is inspiration, ideation, and implementation. Inspiration includes several activities, which are the identification of the design problem, elaboration of the design brief, and observation of the behavior of the target group. The next phase is ideation, with an emphasis on the synthesis from an interdisciplinary team leading to new solutions. The last phase is implementation where the best ideas are turned into products or an action plan. Another design thinking model proposed by the Stanford dschool (Yang, 2018) includes five steps: (a) empathize, using interviews to seek an understanding of human needs; (b) define, clarifying key people, objectives, and decisions, (c) ideate, prioritizing different ideas, (d) prototype, using mockups to quickly iterate proposed solutions; and (e) test, understanding the feasibility of the solutions. The last model is the Double Diamond proposed by the Design Council (Tschimmel, 2012), which is based on divergent and convergent phases of the design process. It consists of four phases: Discover, Define, Develop, and Deliver. In the discovery phase, the designer is looking for new opportunities and insights. The second stage is the definition stage, which serves as a filter for the selection of the first insights. The third stage is the development and prototyping of the project, and finally, the designers deliver the products and launch them in the market.

Design thinking pedagogy has been implemented in the design classroom. Several important educational values of design thinking have been discussed, including developing students' capacities to answer real-life, illdefined problems, using sketching and modeling to develop nonverbal thoughts and communication, and cultivating hands-on design learning experiences (Renard, 2014). The benefits of design thinking for learners includes developing "creative thinking, critical thinking, problem-solving, meaningful learning, and metacognitive skills... [and progressing] affective skills such as empathy, creative self-confidence, risk-taking, assertiveness, self-sufficiency of knowledge generation, curiosity, being human-oriented and setting a career 
goal." (Avcu \&Er, 2020, p. 5). Noel and Liu (2016) argue that the teaching and learning process in art and design education is a two-way dialog, with the focus on a student-centered approach. They believe that with the use of design thinking, students will have more opportunities to develop curiosity and empathy and with the use of research, experimentation, and critical thinking, students can explore human and environmental needs, which in turn leads to learning success and satisfaction. Gatia (2017) suggests that by using design thinking methodologies, students can find and expedient the path to the right solution more easily. Especially with design teams, design thinking is a powerful tool to eradicate the complexity and disorder, allowing them to focus on the essence of the needs and problems and finally produce workable solutions. In short, design thinking has become a necessity in the tool-box for cultivating designer training.

\section{Purpose of Study}

The purpose of this study is to examine the connection among creativity, imagination, and design thinking of Chinese design undergraduates. We ask two research questions: What is the relationship among creativity, imagination, and design thinking of our participants? Do gender and age affect in these relationships? It is believed that design thinking is highly correlated with creativity and imagination, but this hypothesis has not been verified by empirical data. Therefore, this study attempts to examine the hypothesis and acquire a better understanding and attitudes of design thinking among our students.

\section{Method}

\subsection{Participants}

Convenience sampling was used to enlist 88 first-year Chinese fashion design college students in Taiwan. Of these, $8(9.1 \%)$ were male and $80(90.9 \%)$ were female, and the average age was $18.08(S D=.27)$.

\subsection{Measures}

\subsubsection{Design Thinking}

The Tsai Design Thinking Scale (TDTS; Tsai, 2018) was employed to examine the design thinking profiles of our participants. The TDTS includes 16 items with five Likert-scale ranging from 1 (strongly disagree) to 5 (strongly agree). The TDTS focuses on four components of design thinking: reasoning and reflection, ideation, collaboration, and execution. Tsai (2018) reported high internal consistency and a robust four-dimensional factor solution of the TDTS through confirmatory factor analysis. In addition, in Tsai's (2019) study, the TDTS shows an appropriate tool for capturing design thinking of college students. In other words, the measurement of the TDTS displays its acceptable validity and reliability.

6.2.2 Creativity

The Cognitive Processes Associated with Creativity (CPAC; Miller, 2009) scale was used to investigate the creative potential of our participants. The CPAC scale includes 28 items and measures six dimensions of creativity: idea manipulation, idea generation, flow, imagery/sensory perception, incubation, and metaphorical/analogical thinking. Miller (2009) reported that the internal consistency of the total scale was acceptable $(\alpha=.852)$ and its factor structure supported the six components of creativity. The concurrent validity of the CPAC scale was established by using the Abbreviated Torrance Test for Adults (ATTA; Goff \& Torrance, 2002), the Consensual Assessment Technique (CAT; Amabile, 1982) short story task, and the Creativity Styles Questionnaire-Revised (Kumar \& Holman, 1997).

6.2.3 Imagination

To measure imaginative capability, we used a 29-item Imaginative Capability Scale (ICS; Lin et al., 2014). The ICS includes three dimensions: initiating imagination, conceiving imagination, and transforming imagination. The ICS uses a 6-point scale ranging from 1 (strongly disagree) to 6 (strongly agree). Hsu, Peng, Wang, and Liang (2014) reported acceptable reliability and construct validity of the ICS.

\section{Results}

\subsection{Correlational Analysis}

Table 1 shows the means, standard deviations, and intercorrelations among the six variables (idea manipulation, image/sensory perception, flow, metaphorical/analogical thinking, idea generation, and incubation) of creativity, the three variables (initiating imagination, conceiving imagination, and transforming imagination) of imagination, and the four variables (reasoning/reflection, ideation, collaboration and execution) of design thinking. The relationship among the 13 variables was investigated using the Pearson product-moment correlation coefficient. Almost all of the coefficients were positive and significant $(p<.05)$, with strengths from medium $(r=.26)$ to high $(r=.76)$. Incubation had no significant relationship to transforming imagination $(r=.21)$, reasoning/reflection $(r=.16)$, collaboration $(r=.05)$, and execution $(r=-.16)$. Collaboration and ideation had no significant relationship $(r=.20)$ and execution only had a significant relationship with two variables: reasoning/reflection $(r=.33)$ and collaboration $(r=.40)$. 


\subsection{Group Differences}

In our study, we used an independent-sample t-test to compare the mean scores of the 13 measures of our groups. Table 2 shows that there were no significant differences between males and females.

Multivariate analysis of variance (MANOVA) was employed for our study and the 13 measures of creativity, imagination, and design thinking were viewed as the dependent variables, and gender and age were treated as the independent variables. Because of conducting a series of analyses, we ran the risk of an inflated Type 1 error. In order to minimize for the Type 1 error across the multiple tests, we used a Bonferroni adjustment by dividing .05 by 13 (which equals .004 after rounding) as our cut-off. Table 3 shows that there was no statistically significant difference between males and females for the combined dependent variables, $F(13,72)$ $=.94, p=.516$, Wilks's Lambda $=.86$, partial eta squared $=.145$. When the results for the dependent variables were considered separately, there was no difference in statistical significance via the Bonferroni adjusted alpha level of .005 . In terms of age, there was no statistically significant difference among the different ages for the combined dependent variables, $F(13,72)=.35, p=.981$, Wilks's Lambda $=.94$, partial eta squared $=.059$. When the results for the dependent variables were considered separately, there was no difference in statistical significance via the Bonferroni adjusted alpha level of .005 . With regard to the interaction between gender and age, again, there was no statistically significant difference for the combined dependent variables, $F(13,72)=.94$, $p=.702$, Wilks's Lambda $=.88$, partial eta squared $=.12$. In addition, when the results for the dependent variables were considered separately, there was no difference in statistical significance via the Bonferroni adjusted alpha level of .005 .

\subsection{Structural Equation Modeling}

Structural equation modeling with a maximum likelihood estimation was performed using IBM AMOS to examine the model structure. We used the indicators recommended by Hair et al. (2010, pp. 746-753) to assess goodness of model fit: Goodness-of-Fit Index (GFI; greater than .90 is typically considered good), Comparative Fit Index (CFI; above .90 usually indicates a good fit), Incremental Fit Index (IFI; above .90 usually indicates a good fit), Root Mean Square Error of Approximation (RMSEA; lower than .08 indicates an acceptable fit), and Standardized Root Mean Residual (SRMR; lower than .1 suggests a good fit). The results demonstrate that the model yielded an acceptable model fit: $\mathrm{X} 2=87.18, d f=57, p=.006$, GFI $=.877, \mathrm{CFI}=.955, \mathrm{IFI}=.957$, $\mathrm{RMSEA}=.078, \mathrm{SRMR}=.052$. Figure 1 illustrates the factor loadings results from .17 to .90 and correlations among the three latent variables, ranges from .85 to .96 ; all coefficients were significant at $p<.001$, except for execution with $p=.12$.

\section{Discussion}

The main objective of this study was to examine the relationship among creativity, imagination, and design thinking of Chinese design college students in Taiwan. According to zero-order correlation, we found that the strength of correlations among the six creativity, three imagination, and four design thinking variables were between medium and high. This finding is also observed by other studies (Hsu et al., 2014). However, we found incubation was not related to transforming imagination, reasoning/reflection, collaboration, and execution. It is likely that during the imagination process, incubation plays a certain role in provoking imaginative ideas in the stage of initiating imagination and conceiving imagination, but when exercising the imaginative ideas in the stage of transforming imagination, we normally do not need incubation to achieve the goal. Similarly, it seems that incubation does not have an influence on in reasoning, collaboration, and execution of the design thinking process.

In terms of design thinking, we found that reasoning/reflection and collaboration were related to creativity and imagination, but the execution was not related to creativity and imagination. It is likely that during the design process, we still need some level of creativity and imagination to discover the issues and reflect on the context in order to identify the strength and weakness of the current status of the design. In addition, in the group environment, when designers are working with others, they still need creativity and imagination to generate better design ideas. However, in the execution of design ideas, creativity and imagination may not play an important role in successfully implementing the action plans.

With regard to the gender differences in creativity, imagination, and design thinking, no significant difference among groups was found. Additionally, when we included age and the interaction between gender and age in our model, no significant difference was also found. It seems that age and gender did not affect creativity, imagination, and design thinking of our sample.

Structural equation modeling was also employed to further validate these relationships among creativity, imagination, and design thinking. We found that the relationships among creativity, imagination, and design thinking were strong and positive, from $r=.855$ to $r=.956$. It seems that this robust result extends the existing literature, sheds lights on future studies, and provides some practical implications. Most importantly, the current study supports the empirical evidence of the relationship between design thinking and creativity and imagination. 


\section{Limitations}

Before concluding our remarks, some salient limitations should be considered. First, the cross-sectional design of the current study may not provide the explanation of causal relations among creativity, imagination, and design thinking. Longitudinal or experimental designs could be used to further consolidate these findings. Second, although the results show that the model is acceptable, high correlations between some of the variables were found that might affect predictive validity. A third limitation is the use of self-reported measures and it is suggested that further studies could use real-life performance of individuals' creativity, imagination, and design thinking. Finally, homogeneous sample was used in the current study and further researcher could conduct crosscultural studies to validate our findings.

\section{Implications}

The current study provides some significant insights to design education professionals. Educators should not only consider how to include creativity and imagination into their design thinking curricula, but also how to cultivate these important attributes among their design students.

In our study, we found the empirical evidence of a highly correlated relationship between design thinking and creativity and imagination. It suggests that when teachers use real-life design projects to facilitate the design thinking of their students, they should also provide proper stimuli to develop the creativity and imagination of their students. By doing so, they can help students generate better design solutions. This training process may be time consuming, but this practice is promising.

\section{Conclusions}

The major goal of this study was to inspect the relationship among creativity, imagination, and design thinking of design undergraduates in Taiwan. Two major findings were found. Creativity, imagination, and design thinking were positively correlated among our Chinese undergraduates, and these correlations were strong. Further, age and gender did not play a role in these relationships. Some salient limitations were discussed in this study, but the results provide its significant value in the literature. It is believed that this line of research is promising. Additionally, design thinking, creativity, and imagination of design students should be encouraged and facilitated through proper training and practice in the classroom. The possible future research could be stressed on design thinking in K-12 education. Educational practice as well as assessment and policies of supportive design thinking at schools that facilitate the adoption of design thinking in K-12 educational institutions are both important to activate design thinking practice in K-12 education.

\section{References}

Amabile, T. M. (1982). Social psychology of creativity: A consensual assessment technique. Journal of Personality and Social Psychology, 45, 997-1013.

Avcu, Y. E. \&Er, K. E. (2020). Design Thinking Applications in Teaching Programming to Gifted Students. Journal of Educational Technology \& Online Learning, 3(1), 1-30.

Brown, T. (2008). Design thinking. Harvard Business Review, 86(6), 84-92.

Florida, R. (2002). The rise of the creative class: And how it's transforming work, leisure, community, and everyday life. New York, NY: Basic Books.

Csikszentmihalyi, M., \& Nakamura, J. (2006). Creativity through the life span from an evolutionary systems perspective. In C. Hoare (Ed.), Handbook of adult development and learning (pp. 243-254). New York, NY: Oxford University Press.

Gaut, B. (2003). Creativity and imagination. In B. Gaut, \& P. Livingston (Eds.), The creation of art (pp.148-173). Cambridge, UK: Cambridge University Press.

Goff, K., \& Torrance, E. P. (2002). Abbreviated Torrance test for adults manual. Bensenville, IL: Scholastic Testing Service.

Gatia, H. L. (2017). Design thinking in the scope of strategic and collaborative design. Strategic Design Research Journal, 10(1), 30-35.

Guilford, J. P. (1950). Creativity. American Psychologist, 5(9), 444-454. doi:10.1037/h0063487

Hair, J. F., Black, W. C., Babin, B. J., Anderson, R. E., \& Tatham, R. L. (2010). Multivariate data analysis. Upper Saddle River, NJ: Pearson.

Hennessey, B. A., \& Amabile, T. M. (2010). Creativity. Annual Review of Psychology, 61(1), 569-598.

Hsu, Y., Peng, L.-P., Wang, J.-H., \& Liang, C. (2014). Revising the Imaginative Capability and Creative Capability Scales: Testing the relationship between imagination and creativity among agriculture students. International Journal of Learning, Teaching and Educational Research, 6(1), 57-70.

Kangas, K., Seitamaa-Hakkarainen, P., \& Hakkarainen, K. (2013). Design thinking in elementary students' collaborative lamp designing process. Design and Technology Education: An International Journal, 18(1), $30-43$. 
Kaufmann, G. (2003). Expanding the mood-creativity equation. Creativity Research Journal, 15(2/3), 131-135.

Kaufman, J. C., \& Baer, J. (2006a). An Introduction to the special issue: A tribute to E. Paul Torrance. Creativity Research Journal, 18(1), 1-2. doi:10.1207/s15326934crj1801_1

Kumar, V. K., \& Holman, E. R. (1997). The Creativity Styles Questionnaire-Revised. Unpublished psychological test. Department of Psychology, West Chester University of Pennsylvania, West Chester, PA.

Lin, W. -S., Hsu, Y., \& Liang, C. (2014). The mediator effects of conceiving imagination on the academic performance of design students. International Journal of Technology and Design Education, 23(4), 10371046. doi: 10.1007/s10798-013-9244-x

Marks, D. F. (1995). New directions for mental imagery research. Journal of Mental Imagery, 19(3-4), 153-167.

Miller, A. L. (2009). Cognitive processes associated with creativity: Scale development and validation. Muncie, IN: Ball State University. Retrieved from http://cardinalscholar.bsu.edu/763/1/Amiller 2009-2 BODY.pdf

Morosini, P. (2010). Seven keys to imagination: Creating the future by imagining the unthinkable and delivering it. London, UK: Marshall Cavendish.

Noel, L., \& Liu, T.L. (2016). Using Design Thinking to create a new education paradigm for elementary level children for higher student engagement and success. Proceedings of DRS 2016, Design Research Society 50th Anniversary Conference. Brighton, UK, 27-30 June 2016.

Owen, C. (2006). Design thinking: Notes on its nature and use. Design Research Quarterly, 1(2), 16-27.

Renard, H. (2014). Cultivating design thinking in students through material inquiry. International Journal of Teaching and Learning in Higher Education, 26(3), 414-424.

Richardson, A. (1969). Mental imagery. New York, NY: Springer.

Runco, M. A. (2004). Creativity. Annual Review of Psychology, 55(1), 657-687. doi:10.1146/annurev.psych.55.090902.141502

Runco, M. A. (2010). Education based on a parsimonious theory of creativity. In R. A. Beghetto \& J. C. Kaufman (Eds.), Nurturing creativity in the classroom (pp. 235-251). New York, NY: Cambridge University Press.

Runco, M. A., \& Jaeger, G. J. (2012). The standard definition of creativity. Creativity Research Journal, 24(1), 92-96.

Russ, S. W. (1993). Affect and creativity: The role of affect and play in the creative process. Hillsdale, NJ: Lawrence Erlbaum Associates.

Russ, S. W., \& Kaugars, A. (2000). Emotion in children's play and creative problem solving. Creativity Research Journal, 13(2), 211-219.

Russ, S. W., \& Schafer, E. D. (2006). Affect in fantasy play, emotion in memories, and divergent thinking. Creativity Research Journal, 18(3), 347-354. doi:10.1207/s15326934crj1803 9

Scheer, A., Noweski, C., \& Meinel, C. (2012). Transforming constructivist learning into action: Design thinking in education. Design and Technology Education, 17(3), 8-19.

Simonton, D. K. (2012). Teaching creativity: Current findings, trends, and controversies in the psychology of creativity. Teaching of Psychology, 39(3), 217-222.

Sternberg, R. J. (Ed.) (1999). Handbook of creativity. Cambridge, UK: Cambridge University Press.

Sternberg, R. J., \& O’Hara, L. A. (2000). Intelligence and creativity. In R. J. Sternberg (Ed.), Handbook of intelligence (pp. 611-630). New York, NY: Cambridge University Press.

Taylor, M. (1999). Imaginary companions and the children who create them. New York, NY: Oxford University Press.

Thurstone, L. L., \& Thurstone, T. G. (1965). Primary mental abilities. Chicago, IL: Science Research Associates.

Torrance, E. P. (1974). Torrance tests of creative thinking: Norms-technical manual. Bensenville, IL: Scholastic Testing Service.

Tsai, K. C. (2012). Play, imagination, and creativity: A brief literature review. Journal of Education and Learning, 1(2), 15-20.

Tsai, K. C. (2018). Development of the Tsai Design Thinking Scale. Arts and Design Studies, 69, 44-54.

Tsai, K. C. (2019). Does personality provide indicators of design thinking capacity? Journal of Studies in Education, 9(2), 80-91.

Tschimmel, K. (2012). Design thinking as an effective toolkit for innovation. In: ISPIM Conference Proceedings of the International Society for Professional Innovation Management (ISPIM). https://doi.org/10.13140/2.1.2570.3361

Warnock, M. (1976). Imagination. Berkeley, CA: University of California Press.

Yang, C.-M. (2018). Applying design thinking as a method for teaching packaging design. Journal of Education and Learning, 7(5), 52-61.

Yang, C. M., \& Hsu, T. F. (2020). Integrating design thinking into a packaging design course to improve students' creative self-efficacy and flow experience. Sustainability, 12(15), 5929. 
Table 1. Zero-order correlations, means, and standard deviations for the study variables

\begin{tabular}{|c|c|c|c|c|c|c|c|c|c|c|c|c|c|}
\hline Variable & $\mathrm{C} 1$ & $\mathrm{C} 2$ & C3 & C4 & $\mathrm{C} 5$ & C6 & I1 & $\mathrm{I} 2$ & I3 & D1 & D2 & D3 & D4 \\
\hline $\mathrm{C} 1$ & -- & & & & & & & & & & & & \\
\hline $\mathrm{C} 2$ & $.67 * *$ & -- & & & & & & & & & & & \\
\hline C3 & $.62 * *$ & $.73 * *$ & -- & & & & & & & & & & \\
\hline $\mathrm{C} 4$ & $.73 * *$ & $.61 * *$ & $.51 * *$ & -- & & & & & & & & & \\
\hline C5 & $.72 * *$ & $.71 * *$ & $.60 * *$ & $.65^{* *}$ & -- & & & & & & & & \\
\hline C6 & $.39 * *$ & $.32 * *$ & $.33 * *$ & $.26^{*}$ & $.41 * *$ & -- & & & & & & & \\
\hline I1 & $.70 * *$ & $.76^{* *}$ & $.63 * *$ & $.57 * *$ & $.67 * *$ & $.36 * *$ & -- & & & & & & \\
\hline $\mathrm{I} 2$ & $.75^{* *}$ & $.65^{* *}$ & $.61 * *$ & $.59 * *$ & $.61 * *$ & $.34 * *$ & $.75^{* *}$ & -- & & & & & \\
\hline I3 & $.62 * *$ & $.60 * *$ & $.50 * *$ & $.57 * *$ & $.62 * *$ & .21 & $.73 * *$ & $.71 * *$ & -- & & & & \\
\hline D1 & $.60 * *$ & $.46^{* *}$ & $.41 * *$ & $.43 * *$ & $.49 * *$ & .16 & $.50 * *$ & $.63 * *$ & $.48 * *$ & -- & & & \\
\hline D2 & $.44 * *$ & $.47 * *$ & $.44 * *$ & $.31 * *$ & $.44 * *$ & $.28 * *$ & $.68 * *$ & $.50 * *$ & $.48 * *$ & $.45^{* *}$ & -- & & \\
\hline D3 & $.30 * *$ & $.31 * *$ & $.38 * *$ & $.31 * *$ & $.32 * *$ & .05 & $.27^{*}$ & $.22 *$ & $.32 * *$ & $.33 * *$ & .20 & -- & \\
\hline D4 & .13 & .20 & .07 & .11 & .16 & -.16 & .07 & .15 & .13 & $.33 * *$ & .17 & $.40 * *$ & -- \\
\hline$M$ & 3.60 & 3.59 & 4.13 & 3.57 & 3.59 & 2.85 & 3.75 & 3.59 & 3.84 & 3.95 & 3.75 & 3.82 & 3.52 \\
\hline$S D$ & .59 & .53 & .59 & .68 & .51 & .68 & .57 & .57 & .61 & .53 & .66 & .61 & .60 \\
\hline
\end{tabular}

Note. $\mathrm{C} 1$ = idea manipulation; $\mathrm{C} 2=$ image/sensory; $\mathrm{C} 3=$ flow; $\mathrm{C} 4=$ metaphorical/analogical thinking; $\mathrm{C} 5=\mathrm{idea}$ generation; $\mathrm{C} 6$ = incubation; I1 = initiating imagination; I2 = conceiving imagination; I3 = transforming imagination; D1 = reasoning/reflection ; D2 = ideation ; D3 = collaboration ; D4 = execution.

$* p<.05$.

$* * p<.01$.

Table 2. Gender differences for study variables

\begin{tabular}{|l|c|c|c|c|c|c|}
\hline \multicolumn{1}{|c|}{ Variable } & \multicolumn{2}{c|}{ Male } & \multicolumn{2}{c|}{ Female } & & \\
\hline Idea manipulation & $M$ & $S D$ & $M$ & $S D$ & $t(86)$ & $p$ \\
\hline Image/sensory & 3.53 & .38 & 3.61 & .61 & -.37 & .709 \\
\hline Flow & 3.69 & .48 & 3.58 & .54 & .55 & .589 \\
\hline Metaphorical/analogical thinking & 4.22 & .54 & 4.12 & .59 & .44 & .658 \\
\hline Idea generation & 3.47 & .36 & 3.58 & .70 & -.46 & .649 \\
\hline Incubation & 3.56 & .56 & 3.59 & .50 & -.16 & .877 \\
\hline Initiating imagination & 3.00 & .73 & 2.83 & .68 & .66 & .514 \\
\hline Conceiving imagination & 4.06 & .60 & 3.72 & .57 & 1.60 & .114 \\
\hline
\end{tabular}




\begin{tabular}{|l|c|c|c|c|c|c|}
\hline & \multicolumn{2}{c|}{ Male } & \multicolumn{2}{c|}{ Female } & & \\
\hline \multicolumn{1}{|c|}{ Variable } & $M$ & $S D$ & $M$ & $S D$ & $t(86)$ & $p$ \\
\hline Transforming imagination & 3.88 & .50 & 3.83 & .62 & .19 & .852 \\
\hline Reasoning/reflection & 3.88 & .51 & 3.96 & .54 & -.44 & .661 \\
\hline Ideation & 3.92 & .35 & 3.73 & .68 & .75 & .454 \\
\hline Collaboration & 3.78 & .47 & 3.82 & .62 & -.19 & .847 \\
\hline Execution & 3.38 & .65 & 3.53 & .59 & -.69 & .490 \\
\hline
\end{tabular}

Table 3. Multivariate and univariate analyses of variance for the study variables

\begin{tabular}{|l|c|c|c|c|c|c|c|c|c|c|c|c|c|c|}
\hline & & \multicolumn{10}{|c|}{ ANOVA $F(1,87)$} \\
\hline Variable & $\begin{array}{c}\text { MANOVA } \\
F(13,72)\end{array}$ & C1 & C2 & C3 & C4 & C5 & C6 & I1 & I2 & I3 & D1 & D2 & D3 & D4 \\
\hline $\begin{array}{l}\text { Gender } \\
\text { G) }\end{array}$ & .94 & 3.26 & .64 & .10 & .42 & .63 & .57 & .12 & 1.08 & .07 & 1.09 & .19 & .06 & .28 \\
\hline Age (A) & .35 & .25 & .23 & .61 & .25 & .40 & 1.08 & .01 & .03 & .10 & .03 & .34 & .06 & .00 \\
\hline G x A & .76 & 3.92 & 2.17 & .62 & .17 & .82 & .78 & .73 & 1.84 & .25 & .88 & 1.39 & .22 & .01 \\
\hline
\end{tabular}

Note. Multivariate $F$ rations are Wilks's Lambda statistic. All $F$ rations were not significant. $\mathrm{C} 1=$ idea manipulation; $\mathrm{C} 2$ = image/sensory; $\mathrm{C} 3$ = flow; $\mathrm{C} 4=$ metaphorical/analogical thinking; $\mathrm{C} 5$ = idea generation; $\mathrm{C} 6$ = incubation; I1 = initiating imagination; I2 = conceiving imagination; I3 = transforming imagination; D1 = reasoning/reflection; D2 = ideation ; D3 = collaboration ; D4 = execution.

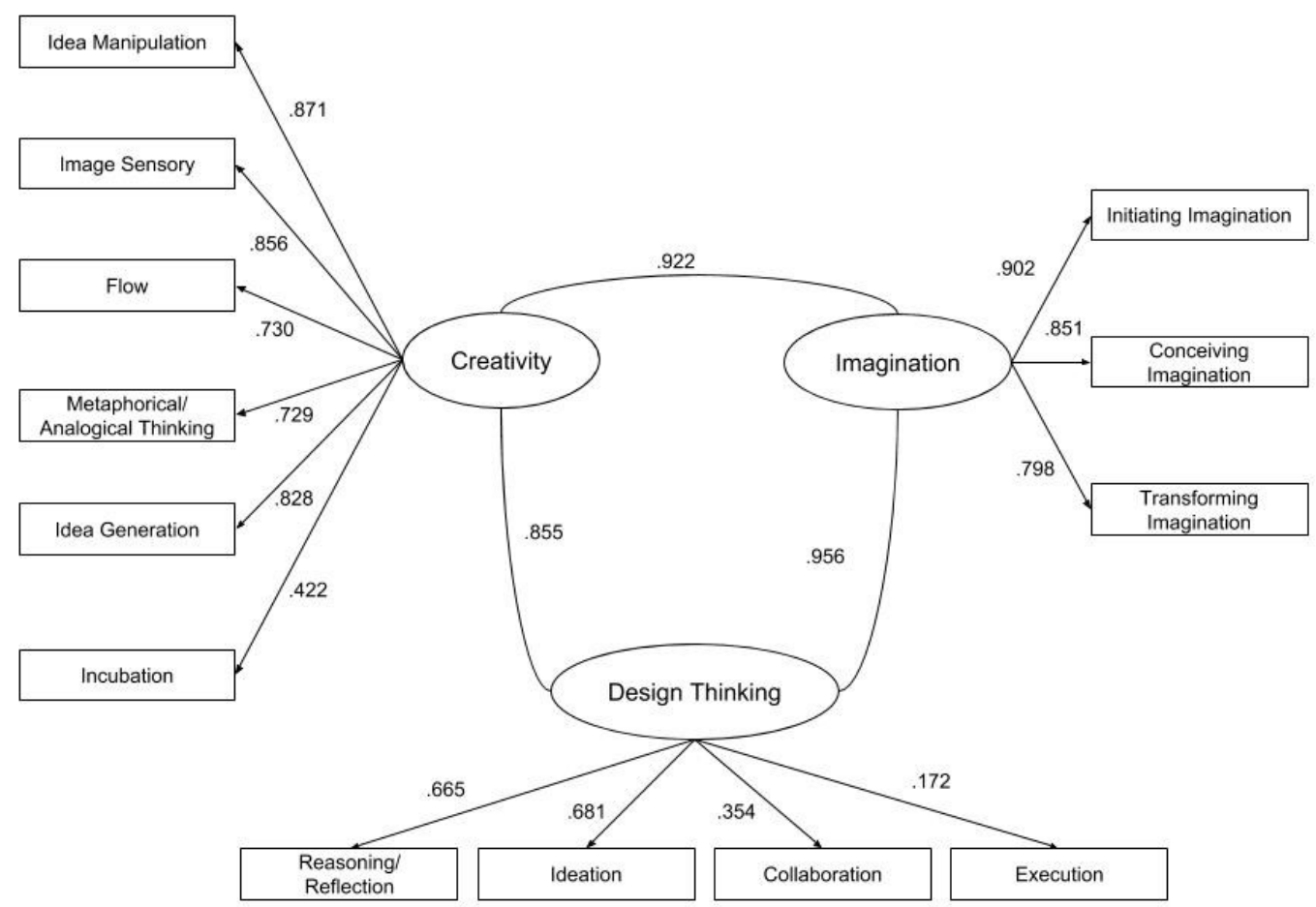

Figure 1. Proposed Model of Creativity, Imagination, and Design Thinking. 